Article

\title{
Physicochemical Characterization and Immunomodulatory Activity of a Novel Acid Polysaccharide from Solanum muricatum
}

\author{
Heng Yue ${ }^{1,2}$, Qianqian Xu ${ }^{1,2}$, Xianheng $\mathrm{Li}^{1,2}$, Jeevithan Elango ${ }^{1,2} \mathbb{D}$, Wenhui Wu ${ }^{1,2, *(\mathbb{D})}$ and \\ Jianfeng $X u^{1,2, *}$ \\ 1 Department of Biopharmaceutics, College of Food Science and Technology, Shanghai Ocean University, \\ Shanghai 201306, China; YHSHOU1234@163.COM (H.Y.); xyqq0714@163.com (Q.X.); \\ lixhishou@163.com (X.L.); srijeevithan@gmail.com (J.E.) \\ 2 Quality Supervision, Inspection and Testing Center for Cold Storage and Refrigeration Equipment, \\ Ministry of Agriculture, Shanghai 201306, China \\ * Correspondence: whwu@shou.edu.cn (W.W.); jfxu@shou.edu.cn (J.X.)
}

Received: 10 October 2019; Accepted: 18 November 2019; Published: 30 November 2019

\begin{abstract}
To investigate the structure and immunomodulatory activity of polysaccharide from Solanum muricatum, a novel acid polysaccharide named SMP-3a was purified from Solanum muricatum pulp through DEAE-52 cellulose column and Sephadex G-200 chromatography. Monosaccharide composition analysis showed that SMP-3a was mainly composed of rhamnose, arabinose, galactose, and galacturonic acid with the molar ratio of 1.09:2.64:1.54:1. The average molecular weight was found to be $227 \mathrm{kDa}$ by high performance gel permeation chromatography (HPGPC). Thermal studies revealed the SMP-3a was a thermally stable polymer. Based on the results of methylation and NMR analysis, the backbone chain of SMP-3a was composed of $\rightarrow 2)-\alpha$-L-Rhap- $(1 \rightarrow, \rightarrow 4)-\alpha-\mathrm{D}-\mathrm{Gal} p \mathrm{~A}-(1 \rightarrow$ and $\rightarrow 4)-\alpha-\mathrm{D}-G a l p-(1 \rightarrow$. The side chain was consisted of $\alpha$-L-Araf-( $\rightarrow$ and $\rightarrow 5)-\alpha$-L-Araf- $(1 \rightarrow$. Immunomodulatory assay indicated that SMP-3a could significantly promote the proliferation of macrophages and stimulate the secretion of cytokines, including TNF- $\alpha$, IL-1 $\beta$, and IL- 6 . Our results suggested that SMP-3a could be used as a novel potential immunomodulatory agent in functional food.
\end{abstract}

Keywords: polysaccharide; Solanum muricatum; purification; structural characterization; immunomodulatory activity

\section{Introduction}

Solanum muricatum, which belongs to the Solanaceae family, is an herbaceous plant originally cultivated in the Andean region of South America and has been disseminated throughout the world. It is commonly called pepino or melon pear and can be grown under diverse soil and climatic conditions [1,2]. The color of Solanum muricatum begins green and changes to golden yellow covered with purple stripes during the ripening period [3]. This fruit is rich in minerals such as calcium, potassium, and phosphorous. It also contains vitamins such as ascorbic acid, niacin, riboflavin, and thiamin, which are ideal for a number of metabolic and antioxidant reactions [4]. The analysis of volatile aromatic constituents of Solanum muricatum have shown that Solanum muricatum contains terpenes and $\beta$-damascenone, which contributes to the exotic aromas of the food [5]. Besides, this plant food is rich in phenolic acids and flavonoids [6].

Polysaccharides are one kind of biological macromolecules composed of more than 10 monosaccharides. They are usually important and main bioactive constituents with complex structure of plants, fungi, and seaweed. In recent years, natural polysaccharides have attracted 
widespread attention due to their structural diversity, low toxicity, and unique biological activity, especially the immunomodulatory activity [7-10]. A large proportion of the current research focused on the activity of polysaccharides has shown that the natural polysaccharides extracted from plants possess a wide variety of biological activity, such as immunomodulatory, antitumor, and antioxidant effects $[8,11,12]$. The biological activity of polysaccharides is related to monosaccharide composition, molecular weight, glycosidic linkage, and chemical structure [13]. Thus, the systematic characterization of the structure of polysaccharides is an important first step for the study of biological activity on polysaccharides.

Previous studies on Solanum muricatum mainly involved the activity of aqueous and ethanol extracts $[4,6]$. However, studies on the polysaccharides from Solanum muricatum are limited. Therefore, this study aimed to obtain a purified polysaccharide from the pulp of Solanum muricatum using hot water extraction, to characterize the purified polysaccharide, and to study the immunoregulatory activity of the purified polysaccharide.

\section{Materials and Methods}

\subsection{Materials and Reagents}

The Solanum muricatum was purchased from a local supermarket in Wuwei City, Gansu Province of China. The Solanum muricatum was washed in flowing tap water to remove impurities. The washed Solanum muricatum was cut into thin slices and then dried in an electro-thermostatic blast oven (DHG-9053A, Shanghai Yiheng Scientific Instrument Co., Shanghai, China) at $50^{\circ} \mathrm{C}$. The dried Solanum muricatum was then crushed and sieved through a 60 mesh sieve to obtain Solanum muricatum powder.

DEAE-52 cellulose and Sephadex G-200 were purchased from Shanghai Yuanye Biotechnology Co. (Shanghai, China). Standard monosaccharides (rhamnose, fucose, arabinose, xylose, mannose, glucose, galactose) were purchased from Sigma Chemical Co. (St. Louis, MO, USA). Lipopolysaccharide (LPS) was obtained from Beyotime Institute of Biotechnology (Shanghai, China). Dulbecco's modified Eagle medium (DMEM) and fetal bovine serum (FBS) were purchased from Thermofisher Scientific Inc. (Millersburg, PA, USA). CCK-8 was purchased from Dalian Meilun Biotech Co. (Dalian, China). ELISA kits for tumor necrosis factor (TNF- $\alpha$ ), interleukin-1 $\beta$ (IL-1 $\beta$ ), and interleukin-6 (IL-6) were all purchased from Nanjing Jiancheng Bioengineering Institute (Nanjing, China). All other reagents used were of analytical grade unless otherwise specified.

\subsection{Extraction of Crude Polysaccharide (SMP)}

The Solanum muricatum powder was treated with $95 \%$ ethanol at $80^{\circ} \mathrm{C}$ for $6 \mathrm{~h}$ to remove lipids, pigments, monosaccharides, and small molecules. The residue was dried in an electro-thermostatic blast oven at $50{ }^{\circ} \mathrm{C}$ to obtain defatted Solanum muricatum powder. Ten grams of defatted powder was extracted three times with hot distilled water at $90^{\circ} \mathrm{C}$ for $3.5 \mathrm{~h}$. The extract solution was filtered in a Büchner funnel, concentrated to a suitable volume using a vacuum rotary evaporator and stored at $4{ }^{\circ} \mathrm{C}$ overnight. Then the filtrate was centrifuged at 10,000 rpm for $10 \mathrm{~min}$ to remove the residue. The supernatant was collected and mixed with four times volume of absolute ethanol for $10 \mathrm{~h}$. After centrifugation at 12,000 rpm for $10 \mathrm{~min}$, the crude polysaccharide SMP was obtained with the yield of $10.12 \%$ by lyophilized at $-84^{\circ} \mathrm{C}$ (Labconco Corporation, Kansas City, MO, USA).

\subsection{Purification of $S M P$}

After $1 \mathrm{~g}$ of the SMP was dissolved in $25 \mathrm{~mL}$ of the water, the solution was centrifuged at 10,000 rpm for $10 \mathrm{~min}$ to remove the residue. Then $25 \mathrm{~mL} 8 \%$ trichloroacetic acid (TCA) was added into the supernate to remove protein from SMP. The solution was poured in two dialysis bags (3500 MW) in a $2 \mathrm{~L}$ beaker for four days using magnetic stirrer, and the ultrapure water was changed every $6 \mathrm{~h}$. After dialysis, the solution was lyophilized at $-84^{\circ} \mathrm{C}$. The protein-removed SMP was purified sequentially 
by DEAE-52 anion-exchange chromatography and Sephadex G-200 gel filtration chromatography according to the reported method with little modifications [14].

Firstly, the SMP was completely dissolved in the ultrapure water. The solution was filtered $(0.45 \mu \mathrm{m})$ and applied to a DEAE-52 cellulose anion-exchange column $(3 \times 45 \mathrm{~cm})$. Then, the column was eluted with a stepwise $\mathrm{NaCl}$ gradient by $0,0.05,0.1,0.3,0.5$, and $1 \mathrm{M} \mathrm{NaCl}$ solutions at a flow rate of $1 \mathrm{~mL} / \mathrm{min}$. The eluate $(10 \mathrm{~mL} /$ tube $)$ was collected and detected by using the phenol-sulfuric acid method to determine polysaccharide [15]. The main fraction, SMP-3 was collected, dialyzed, and applied to a Sephadex G-200 gel filtration chromatography column $(1.6 \times 50 \mathrm{~cm})$. The column was eluted with ultrapure water at a flow rate of $0.2 \mathrm{~mL} / \mathrm{min}$ and the eluate $(4 \mathrm{~mL} /$ tube) was collected and detected as described above. One purified fraction (SMP-3a) was finally collected for further study.

\subsection{FT-IR Spectrum Analysis}

FT-IR spectrum analysis of SMP-3a was performed at room temperature with a Fourier transform infrared spectrometer (Thermo Fisher Scientific, Waltham, MA, USA) in the range of $4000-400 \mathrm{~cm}^{-1}$. The dried SMP-3a $(2 \mathrm{mg})$ was mixed with $\mathrm{KBr}$ powder and then pressed into $1 \mathrm{~mm}$ pellet for FT-IR analysis.

\subsection{Determination of Molecular Weight}

The molecular weight and homogeneity of SMP-3a were determined by high performance gel permeation chromatography (HPGPC) using Shimadzu HPLC system equipped with a series-connected KS805-804-802 column $(7.8 \mathrm{~mm} \times 300 \mathrm{~mm})$ and a Shimadzu LC-10A RID detector. The columns were calibrated using standard dextrans with various molecular weights $(5.2,11.6,148,273$, and $410 \mathrm{kDa})$ and eluted with $0.05 \mathrm{M} \mathrm{NaCl}$ at a flow rate of $0.8 \mathrm{~mL} / \mathrm{min}$. After calculating the logarithm of molecular weight on standard dextrans, a linear regression analysis was performed between the $\mathrm{Lg}(\mathrm{Mw})$ and retention time (Rt). The molecular weight of SMP-3a was calculated as follows:

$$
\operatorname{Lg}(\mathrm{Mw})=-0.2906 \mathrm{Rt}+13.124
$$

where Rt is the retention time of SMP-3a on HPGPC, Mw is the molecular weight of SMP-3a.

\subsection{Reduction of Carboxyl Groups}

The reduction of uronic acid was conducted according to a previously reported method with little modifications $[16,17]$. SMP-3a $(60 \mathrm{mg})$ was dissolved in $30 \mathrm{~mL}$ distilled water, and then $750 \mathrm{mg}$ 1-ethyl-3-(3-dimethylaminopropyl) carbodiimide (EDC) was added. The $\mathrm{pH}$ value of the reaction mixture was maintained at 4.75 for $3 \mathrm{~h}$ with $0.06 \mathrm{M} \mathrm{HCl}$. Then, $2 \mathrm{M}$ sodium borohydride solution was added slowly to reduce the carbonyl group at room temperature, with $\mathrm{pH}$ controlled at 7 with $4 \mathrm{M}$ $\mathrm{HCl}$. Finally, the reaction mixture was dialyzed against distilled water. The retentate was lyophilized and named as SMP-3a-R.

\subsection{Chemical Components and Monosaccharide Composition Analysis}

Total carbohydrate content of SMP-3a was determined by phenol-sulfuric acid method with D-glucose as the standard [15]. Soluble protein content of SMP-3a was measured by the Bradford method using bovine serum albumin as the standard [18]. The content of uronic acid was determined by the sulfuric acid-carbazole method [19].

The monosaccharide composition of SMP-3a and SMP-3a-R were identified and quantified by gas chromatography (GC) analysis according to the reported method with little modifications [20,21], respectively. Briefly, SMP-3a and SMP-3a-R were hydrolyzed with $2 \mathrm{~mL} 2 \mathrm{M}$ trifluoroacetic acid (TFA) at $100{ }^{\circ} \mathrm{C}$ for $6 \mathrm{~h}$. The excess acid was removed by evaporation. Then the hydrolysate was reduced with $\mathrm{NaBH}_{4}$ for $3 \mathrm{~h}$ followed by neutralization with acetic acid. After the excess boric acid was totally removed by co-distillation with methanol, the residue was acetylated with 1:1 pyridine-acetic 
anhydride for $1 \mathrm{~h}$ at $100^{\circ} \mathrm{C}$. The resulting alditol acetates were analyzed through Shimadzu GCMS-QP 2010 system (Shimadzu, Japan) equipped with a Restek RXI-5 SIL MS column (30 $\mathrm{m} \times 0.25 \mathrm{~mm} \times$ $0.25 \mu \mathrm{m})$. The GC-MS temperature program was increased from $120^{\circ} \mathrm{C}$ to $250{ }^{\circ} \mathrm{C}$ at $3{ }^{\circ} \mathrm{C} / \mathrm{min}$ and maintained for $5 \mathrm{~min}$. Standard monosaccharides (rhamnose, fucose, arabinose, xylose, mannose, glucose, and galactose) were derivatized and subjected to GC-MS analysis under the same conditions.

\subsection{Methylation Analysis of SMP-3a-R}

A significant proportion of uronic acid in SMP-3a makes methylation experiments difficult [20], so the carboxyl group of SMP-3a should be reduced prior to methylation analysis. Methylation analysis of SMP-3a-R was performed as previously described by Needs \& Selvendran (1993) [22]. Briefly, dried sample ( $5 \mathrm{mg}$ ) was dissolved in $1.5 \mathrm{~mL}$ of DMSO. Then, $50 \mathrm{mg} \mathrm{NaOH}$ was added into the bottle and sonicated until the sample was completely dissolved. Methyl iodide $(0.9 \mathrm{~mL})$ was added to the mixture slowly with ice bath cooling. The reaction was stopped with deionized water. Then, the methylated alditols were isolated by adding methylene chloride and water. The organic phase was washed with water three times and dried by rotary evaporation under a vacuum to obtain the permethylated polysaccharide. The methylated polysaccharide was hydrolyzed with $1 \mathrm{~mL} 2 \mathrm{M}$ (TFA) for $6 \mathrm{~h}$ at $100{ }^{\circ} \mathrm{C}$ and reduced with $\mathrm{NaBH}_{4}$ for $8 \mathrm{~h}$. Finally, the reduced product acetylated with $1 \mathrm{~mL}$ acetic anhydride at $100^{\circ} \mathrm{C}$ for $2 \mathrm{~h}$, and the partially methylated alditol acetates (PMAA) were analyzed by GC-MS system (Shimadzu GCMS-QP 2010) equipped with a RXI-5 SIL MS column $(30 \mathrm{~m} \times 0.25 \mathrm{~mm}$ $\times 0.25 \mu \mathrm{m}$ ). The temperature program increased from $120^{\circ} \mathrm{C}$ up to $250{ }^{\circ} \mathrm{C}$ at $3{ }^{\circ} \mathrm{C} / \mathrm{min}$ and held at $250{ }^{\circ} \mathrm{C}$ for $5 \mathrm{~min}$.

\subsection{NMR Analysis}

About $50 \mathrm{mg}$ of SMP-3a was dissolved in $0.5 \mathrm{~mL}$ of $\mathrm{D}_{2} \mathrm{O}$ in an NMR tube, and then the ${ }^{1} \mathrm{H}$ NMR, ${ }^{13} \mathrm{C}$ NMR, NOESY, COSY, HSQC, and HMBC spectra were recorded on a Bruker Ascend $500 \mathrm{MHz}$ spectrometer at room temperature $\left(25^{\circ} \mathrm{C}\right)$.

\subsection{Scanning Electron Microscopy (SEM) Observation}

The microstructure of the SMP-3a was carried out using a S3400N scanning electron microscope (Hitachi LTD., Tokyo, Japan). The freeze-dried SMP-3a was fixed on aluminum tape and coated with a gold layer under reduced pressure. The images were collected at an accelerating voltage of $5.0 \mathrm{kV}$.

\subsection{Thermal Gravimetric Analysis (TGA) and Differential Scanning Calorimetric (DSC) Analysis}

Thermal gravimetric analysis and differential thermal gravity (DTG) of SMP-3a was detected using a thermogravimetric analyzer (TG-209F1, NETZSCH, Selb, Germany). Seven mg SMP-3a was placed in the sample pan and heated from $30{ }^{\circ} \mathrm{C}$ to $500{ }^{\circ} \mathrm{C}$ at a rate of $10{ }^{\circ} \mathrm{C} / \mathrm{min}$ under nitrogen atmosphere. The flow rate of nitrogen was $40 \mathrm{~mL} / \mathrm{min}$.

The thermal stability of SMP-3a was determined by differential scanning calorimetry (DSC1, Mettler, Greifensee, Switzerland) and heated from 25 to $300{ }^{\circ} \mathrm{C}$ at a rate of $10{ }^{\circ} \mathrm{C} / \mathrm{min}$ under nitrogen atmosphere.

\subsection{Immunomodulatory Activity of SMP-3a}

\subsubsection{Cell Culture}

The murine macrophage cell line RAW 264.7 was obtained from the cell bank of Chinese Academy of Science (Shanghai, China). Cells were cultured in DMEM high glucose medium supplemented with $10 \% \mathrm{FBS}, 100 \mathrm{U} / \mathrm{mL}$ penicillin, and $100 \mu \mathrm{g} / \mathrm{mL}$ streptomycin at $37^{\circ} \mathrm{C}$ in a humidified atmosphere incubator (Thermofisher Scientific Inc., Millersburg, PA, USA) with $5 \% \mathrm{CO}_{2}$. 


\subsubsection{RAW264.7 Macrophage Proliferation Assay}

The proliferation effect of SMP-3a on RAW 264.7 cells was determined by the CCK-8 method. Briefly, the RAW264.7 cells were incubated in 96-well plate at a density of $1 \times 10^{5}$ cells $/ \mathrm{mL}$ and cultured for $24 \mathrm{~h}$. Then, the cells were treated with different concentrations $(12.5,25,50,100,200$, or $400 \mu \mathrm{g} / \mathrm{mL})$ of SMP-3a and incubated at $37^{\circ} \mathrm{C}$ with $5 \% \mathrm{CO}_{2}$ humidity environment. LPS $(1 \mu \mathrm{g} / \mathrm{mL})$ was added as positive group. After $24 \mathrm{~h}, 10 \mu \mathrm{L}$ of CCK- 8 solution was added to each well and incubated at $37^{\circ} \mathrm{C}$ for $1 \mathrm{~h}$. The absorbance was detected at $450 \mathrm{~nm}$ using a microplate reader (Bio-Tek, Winooski, VT, USA). The proliferation rate of SMP-3a on RAW 264.7 cells was calculated according to the following equation:

$$
\text { Proliferation rate }(\%)=\mathrm{A}_{\mathrm{s}} / \mathrm{A}_{\mathrm{c}} \times 100 \%
$$

where $A_{s}$ is the absorbance of the sample, $A_{c}$ is the absorbance of the control.

\subsubsection{Measurement of Cytokine Production}

RAW264.7 macrophage cells $\left(1 \times 10^{5}\right.$ cells $\left./ \mathrm{mL}\right)$ were seeded in 48-well plate and cultured for $24 \mathrm{~h}$. After the treatment with different concentrations $(12.5,25,50,100,200$, or $400 \mu \mathrm{g} / \mathrm{mL})$ of SMP-3a and $1 \mu \mathrm{g} / \mathrm{mL}$ LPS (positive control) for $24 \mathrm{~h}$ at $37^{\circ} \mathrm{C}$, the levels of TNF- $\alpha$, IL- $1 \beta$ and IL- 6 were measured by enzyme-linked immunosorbent assay (ELISA) kits according to the manufacturer's instructions.

\subsection{Statistical Analysis}

All of the data were presented as the means \pm standard deviation (SD) obtained from triplicate experiments. The differences between means were assessed by analysis of variance (ANOVA) with Duncan's test using SPSS 23.0 software.

\section{Results and Discussion}

\subsection{Purification of $S M P$}

SMP was purified by DEAE-52 anion-exchange chromatography with various concentrations of $\mathrm{NaCl}$ solutions. One main fraction, SMP-3, was collected through DEAE-52 anion-exchange chromatography (Figure 1A) by elution with $0.3 \mathrm{M}$ of $\mathrm{NaCl}$. As shown in Figure 1B, SMP-3a was finally obtained from SMP-3 in the elution process of the Sephadex G-200 gel filtration column and was chosen for the following study. 

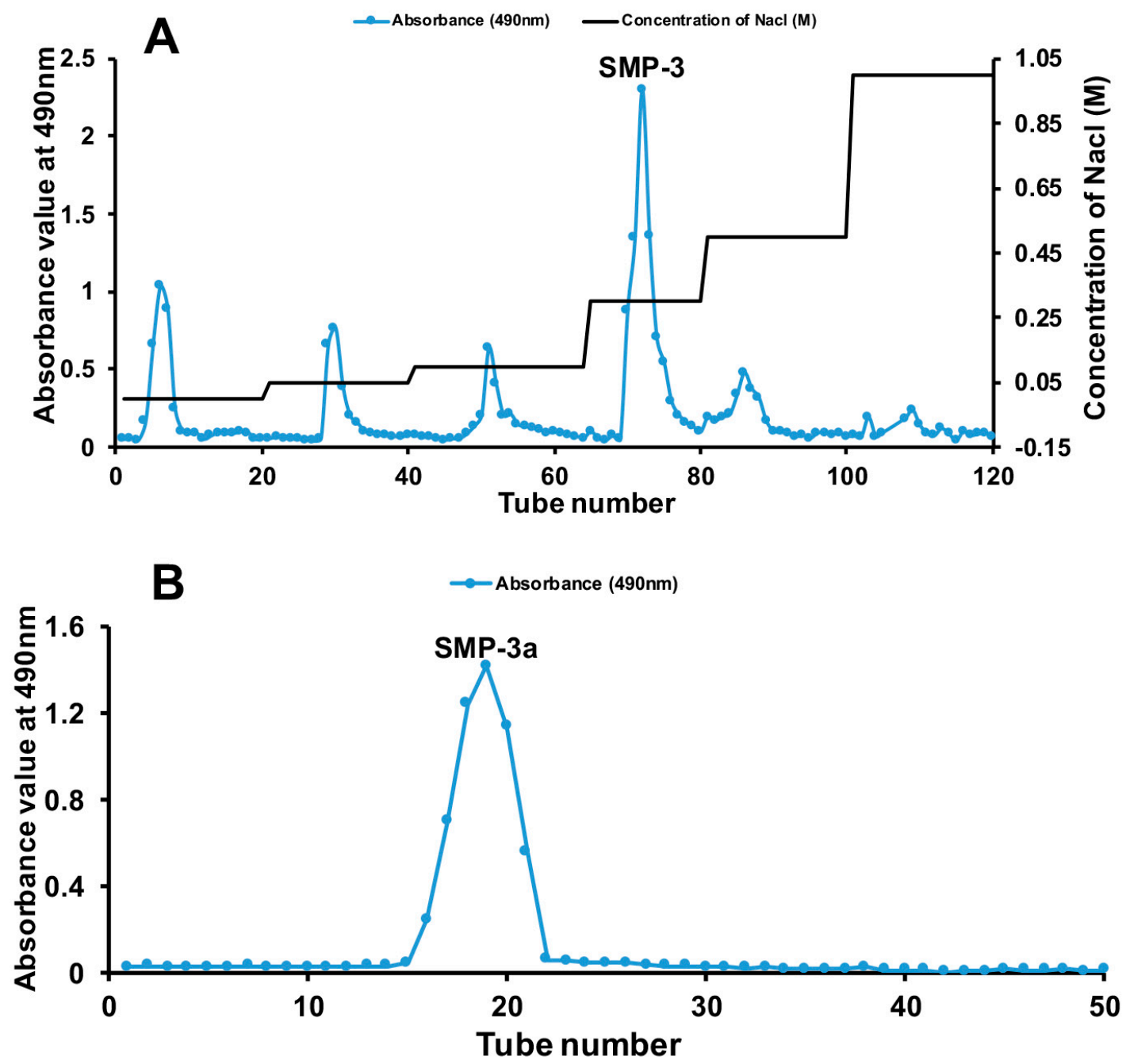

Figure 1. (A) Elution profile of SMP on DEAE-52 anion-exchange chromatography with gradient of $\mathrm{NaCl}$ solution. (B) Elution curve of SMP-3 on Sephadex G-200 gel filtration column with ultrapure water.

\subsection{FT-IR Spectroscopy Analysis}

The FT-IR spectra of SMP-3a ranged from $4000 \mathrm{~cm}^{-1}$ to $400 \mathrm{~cm}^{-1}$ was displayed in Figure 2A, which showed typical absorption peaks of polysaccharide. The absorption peak at $3417.26 \mathrm{~cm}^{-1}$ was assigned to the stretching vibration of O-H. The absorption peak at $2936.84 \mathrm{~cm}^{-1}$ was assigned to the C-H asymmetric stretching vibration. The absorption peak $1603.91 \mathrm{~cm}^{-1}$ was the bending vibration of $\mathrm{O}-\mathrm{H}$ [23]. The absorption peak at $1724.05 \mathrm{~cm}^{-1}$ was assigned to the carboxyl group, which indicated the presence of uronic acid [24]. The band at $1418.87 \mathrm{~cm}^{-1}$ could be due to deforming vibrations of the $\mathrm{C}-\mathrm{H}$ bond [25]. The absorption peak at $1144.68 \mathrm{~cm}^{-1}$ and $1095.4 \mathrm{~cm}^{-1}$ were assigned to the $\alpha$-linkages of arabinofuranoses [26]. The three absorption peaks at $1095.4 \mathrm{~cm}^{-1}, 1073.19 \mathrm{~cm}^{-1}$, and $1033.54 \mathrm{~cm}^{-1}$ indicated the presence of pyranose ring [27]. Based on the analysis above, it can be concluded that SMP-3a is an acidic polysaccharide containing both pyranose and furanose sugars. 

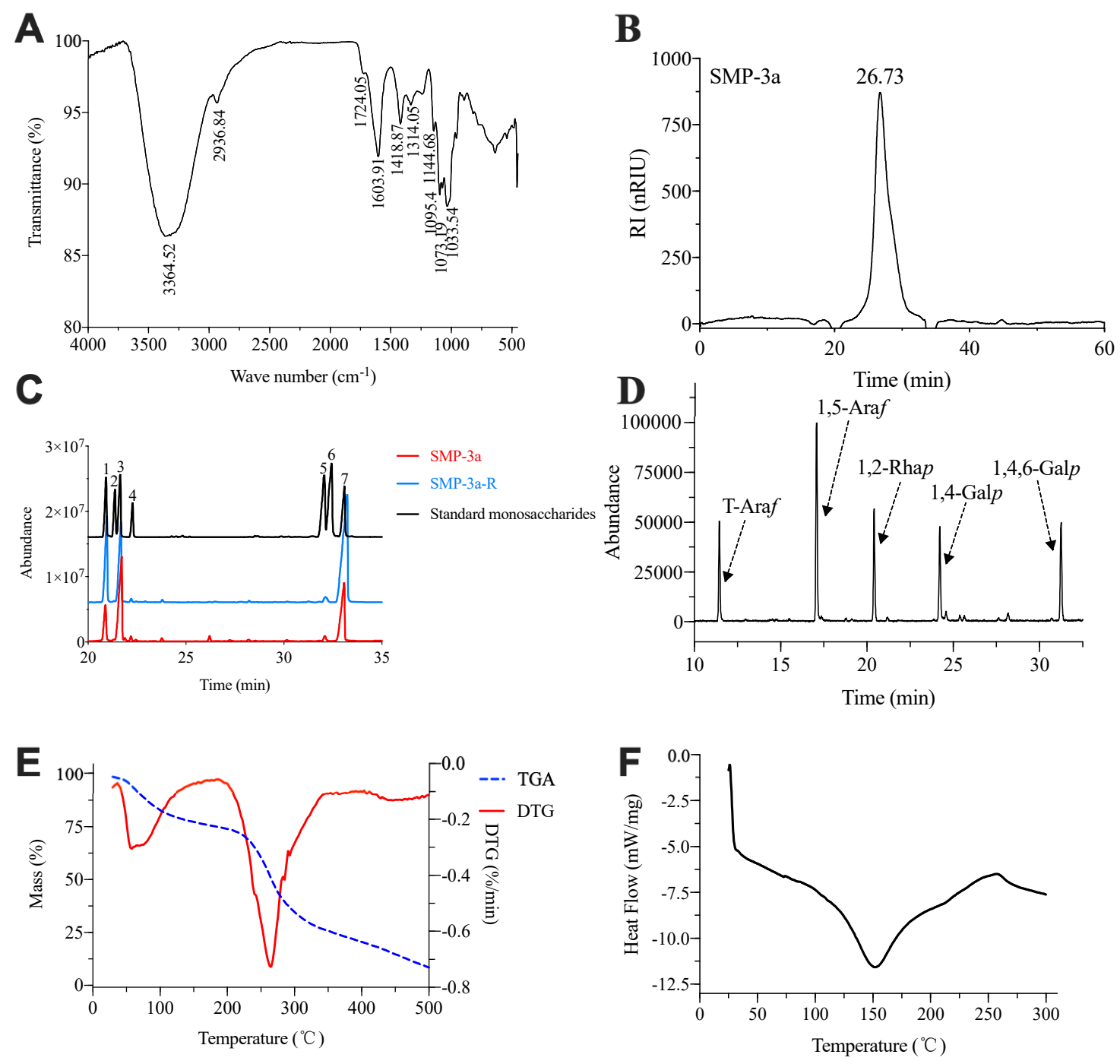

G
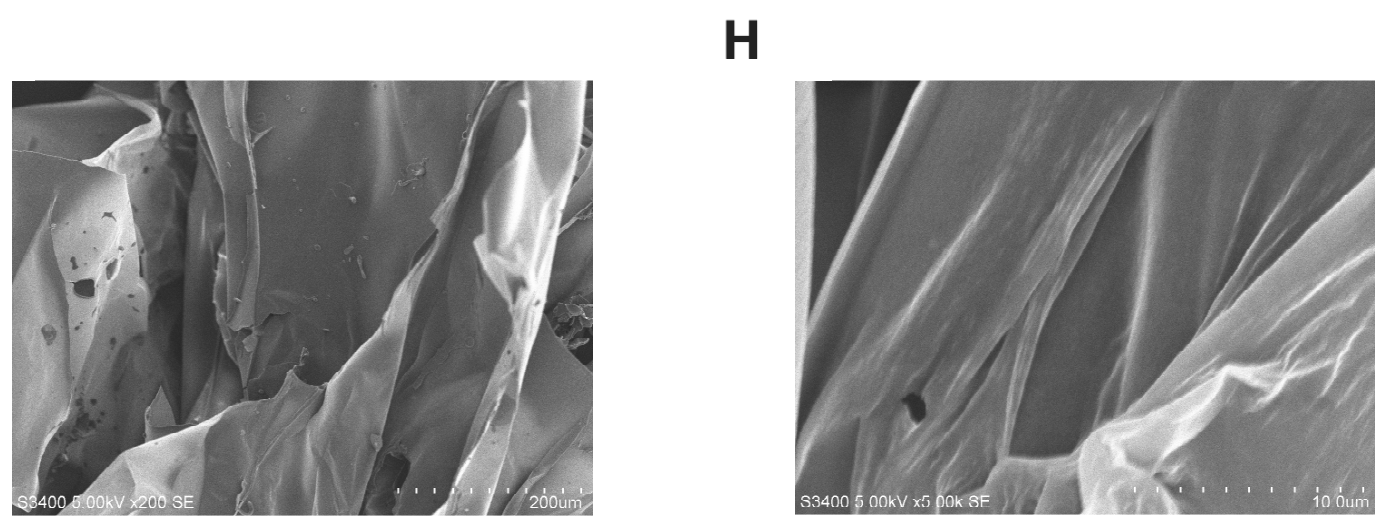

Figure 2. (A) The FT-IR spectrum of SMP-3a. (B) High performance gel permeation chromatography (HPGPC) of SMP-3a. (C) The GC chromatogram profile of SMP-3a, SMP-3a-R and standard monosaccharides. Peak identity: 1. rhamnose, 2. fucose, 3. arabinose, 4. xylose, 5. mannose, 6. glucose, 7. galactose. (D) Total ion chromatogram of the methylated product of SMP-3a-R. (E) TGA and DTG curve of SMP-3a. (F) DSC curve of SMP-3a. (G) Scanning electron microscopy images of SMP-3a (200×). (H) Scanning electron microscopy images of SMP-3a (5000×). 


\subsection{Molecular Weight of SMP-3a}

The homogeneity and average molecular weight of SMP-3a was determined by HPGPC. As shown in Figure 2B, the profile of SMP-3a was a single and symmetrically sharp peak, indicating that the SMP-3a was a homogeneous and pure polysaccharide. The average molecular weight of SMP-3a $(\mathrm{Mw})$ was $2.27 \times 10^{5} \mathrm{Da}(227 \mathrm{kDa})$, which was calculated according to the calibration curve of standard dextrans.

\subsection{Chemical Components and Monosaccharide Composition}

The contents of carbohydrate, protein, and uronic acid in SMP-3a were found to be $87.62 \pm 2.53 \%$, $1.69 \pm 0.68 \%$, and $15.18 \pm 1.05 \%$, respectively. The identity of uronic acid of SMP-3a was confirmed by comparing the monosaccharide composition between SMP-3a and SMP-3a-R, as shown in Figure 2C. According to the results, SMP-3a was mainly consisted of rhamnose, arabinose, galactose, and galacturonic acid with the molar ratio of 1.09:2.64:1.54:1.

\subsection{Methylation Analysis of SMP-3a}

The carboxyl group of SMP-3a was reduced prior to glycosyl linkage analysis due to the presence of galacturonic acid. The results of methylation analysis were presented in Figure 2D and Table 1. Total ion chromatogram of the methylated products of reduced SMP-3a showed that there were five obvious peaks identified as 2,3,5-Me $-\mathrm{Araf}, 2,3-\mathrm{Me}_{2}-\mathrm{Araf}, 3,4-\mathrm{Me}_{2}-\mathrm{Rhap}, 2,3,6-\mathrm{Me}_{3}-\mathrm{Gal} p$, and 2,3-Me $-\mathrm{Me}_{2}-\mathrm{Gal} p$, respectively. This indicated that SMP-3a-R was mainly composed of T-linked-Araf, 1,5-linked-Araf, 1,2-linked-Rhap, 1,4-linked-Gal $p$, and 1,4,6-linked-Gal $p$. Notably, 1,4-linked-Gal $p$ is the reduced form of 1,4-linked-Gal $p$ A. The results of methylation analysis revealed that SMP-3a was consisted of Araf-(1 $\rightarrow, \rightarrow 5)$-Araf- $(1 \rightarrow, \rightarrow 2)$-Rhap- $1 \rightarrow, \rightarrow 4)$-GalpA- $(1 \rightarrow$ and $\rightarrow 4,6)$-Galp-( $1 \rightarrow$ with the molar ratios of 15.7:32.7:18.2:17.7:15.7.

Table 1. GC-MS analysis of the methylated product (alditol acetate) of carboxyl-reduced SMP-3a.

\begin{tabular}{|c|c|c|c|c|}
\hline $\begin{array}{l}\text { Retention } \\
\text { Time (min) }\end{array}$ & $\begin{array}{l}\text { Methylated Sugar } \\
\text { (Alditol Acetate) }\end{array}$ & $\begin{array}{l}\text { Molar } \\
\text { Ratios }\end{array}$ & Type of Linkage & Mass Fragments $(m / z)$ \\
\hline 11.47 & 2,3,5-Me - -Araf & 1 & Araf $-(1 \rightarrow$ & $71,87,101,117,129,145,161$ \\
\hline 17.11 & $2,3-\mathrm{Me}_{2}-\mathrm{Araf}$ & 2.08 & $\rightarrow 5)$-Araf- $(1 \rightarrow$ & $71,87,99,101,117,129,161,189$ \\
\hline 20.45 & 3,4-Me $-\mathrm{Mh}_{2}$ - & 1.16 & $\rightarrow 2)$-Rhap-1 $\rightarrow$ & $87,101,117,129,143,159,189$ \\
\hline 24.23 & $2,3,6-\mathrm{Me}_{3}-\mathrm{Gal} p$ & 1.13 & $\rightarrow 4)$-Galp-(1 $\rightarrow$ & $87,99,101,113,117,129,131,161,173,233$ \\
\hline 31.26 & $2,3-\mathrm{Me}_{2}-\mathrm{Gal} p$ & 1 & $\rightarrow 4,6)-$ Gal $p-(1 \rightarrow$ & $71,85,87,99,101,117,127,159,161,201$ \\
\hline
\end{tabular}

\subsection{NMR Analysis of SMP-3a}

NMR spectroscopy were employed to illustrate the specific structure of SMP-3a. The ${ }^{1} \mathrm{H}$ NMR spectrum (Figure 3A) of SMP-3a revealed five anomeric proton signals at $\delta 5.00,4.99,5.15,5.16$, and $4.94 \mathrm{ppm}$, which were designated as residues A, B, C, D, and E, respectively. As shown in Figure 3B, the corresponding anomeric carbon signals in ${ }^{13} \mathrm{C}$ NMR spectrum were $\delta 108.81,100.55,100.07,110.50$, and 98.94 according to their correlation with anomeric proton signals in HSQC (Figure 3D). The strong ${ }^{1} \mathrm{H}$ signals at $1.16 \mathrm{ppm}$ and ${ }^{13} \mathrm{C}$ signals at $17.83 \mathrm{ppm}$ elucidated the presence of $-\mathrm{CH} 3$ group of rhamnose [28]. Signals at $175.13 \mathrm{ppm}$ in the ${ }^{13} \mathrm{C}$ NMR corroborated the presence of the uronic acids.

The anomeric proton of residue $A$ was designated at $\delta 5.00 \mathrm{ppm}$, which indicated a $\alpha$-linked residue. In the ${ }^{1} \mathrm{H}-{ }^{1} \mathrm{H}$ COSY spectrum (Figure $3 \mathrm{C}$ ), the correlative signals at $\mathrm{H}-1 / \mathrm{H}-2(5.00 / 4.04 \mathrm{ppm}), \mathrm{H}-2 / \mathrm{H}-3$ (4.04/3.92 ppm), H-3/H-4 (3.92/4.12 ppm), H-4/H-5a (4.12/3.79 ppm), and H-5a/H-5b (3.79/3.72 ppm) gave the chemical shifts of $\mathrm{H}-2, \mathrm{H}-3, \mathrm{H}-4, \mathrm{H}-5 \mathrm{a}$, and $\mathrm{H}-5 \mathrm{~b}$. The corresponding ${ }^{13} \mathrm{C}$ resonances from $\mathrm{C}-1$ to $\mathrm{C}-5$ were determined as $\delta 108.81,82.11,78.05,83.61$, and $68.20 \mathrm{ppm}$ according to their correlation with proton signals in HSQC (Figure 3D). Based on these NMR data and literature [28,29], residue A was deduced as $\rightarrow 5-\alpha$-L-Ara $f-1 \rightarrow$. 

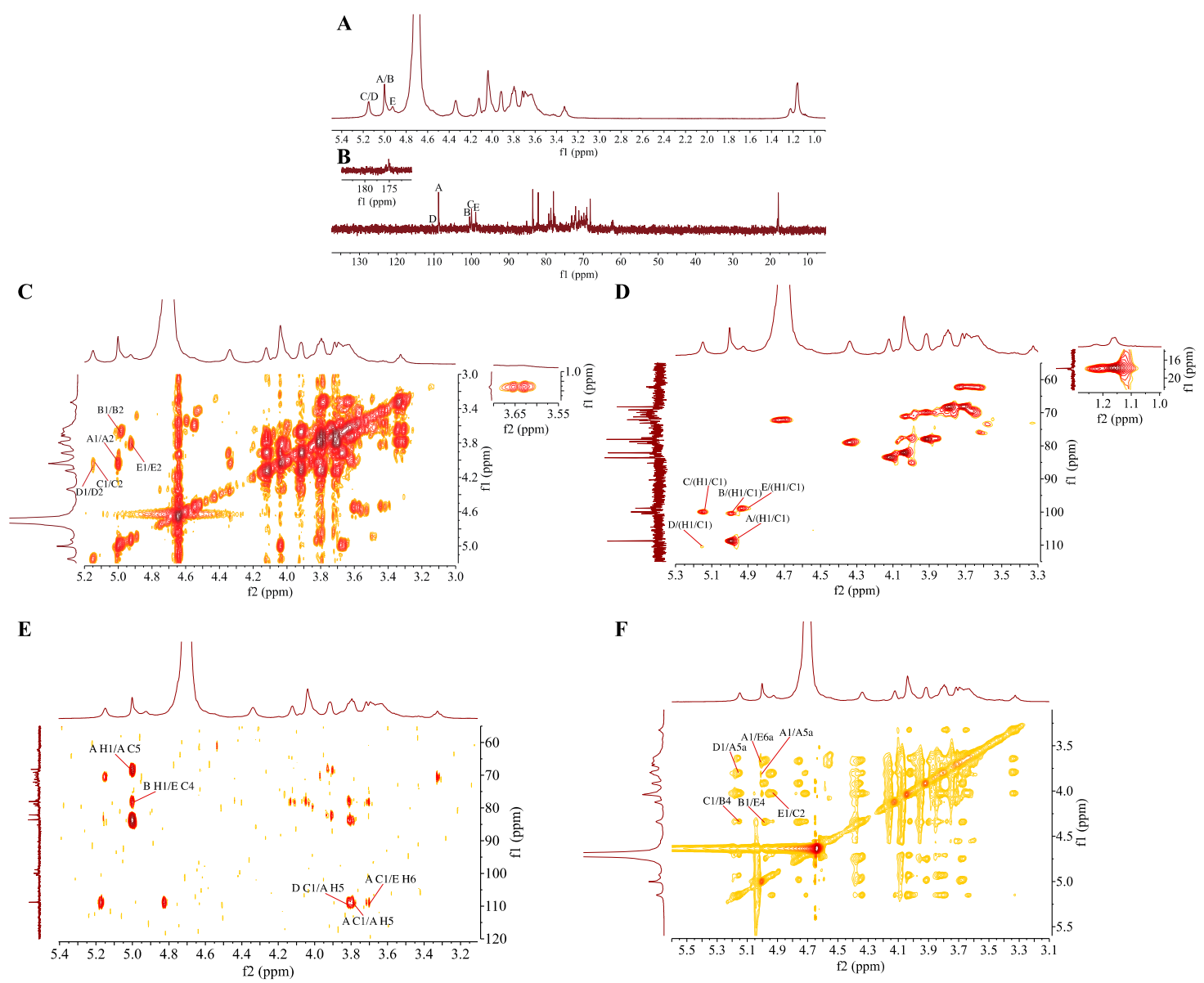

Figure 3. NMR spectrum of SMP-3a recorded at $25{ }^{\circ} \mathrm{C}$ (A) ${ }^{1} \mathrm{H}$ NMR spectrum $(500.13 \mathrm{MHz})$; (B) ${ }^{13} \mathrm{C}$ NMR spectrum (126 MHz); (C) COSY spectrum; (D) HSQC spectrum; (E) HMBC spectrum; (F) NOESY spectrum.

The signal at $\delta 4.99 \mathrm{ppm}$ was assigned to the anomeric proton signal of residue $\mathrm{B}$, indicating a $\alpha$-linked residue. The chemical shifts of $\mathrm{H}-2, \mathrm{H}-3$, and $\mathrm{H}-4$ and were assigned to $\delta 3.67,3.92$, and $4.34 \mathrm{ppm}$ based on the cross-peaks H-1/H-2 (4.99/3.67 ppm), H-2/H-3 (3.67/3.92 ppm), and H-3/H-4 (3.92/4.34 ppm) in the COSY spectrum. H-5 was assigned from the cross-peak H-4/H-5 (4.34/4.71 ppm) in the NOESY spectrum. The corresponding chemical shift from C-1 to C-5 were assigned from the HSQC spectrum. The chemical shift of C-6 was assigned to $\delta 175.13$ ppm from the ${ }^{13} \mathrm{C}$ NMR spectrum. Residue B was designated as $\rightarrow 4)-\alpha-\mathrm{D}-$ GalpA- $(1 \rightarrow[29]$.

The anomeric proton of residue $C$ was assigned at $\delta 5.15 \mathrm{ppm}$, which manifested a $\alpha$-linked residue. The other protons of residue $\mathrm{C}$ were determined from the COSY spectrum and NOESY spectrum. The corresponding carbon signals of C-1 to C-6 were identified on the basis of the correlation between the proton and carbon signals in the HSQC spectrum. In comparison to the reported data [28,29], residue $\mathrm{C}$ was deduced as $\rightarrow 2)-\alpha$-L-Rhap- $(1 \rightarrow$.

As described above, the detailed proton and carbon signals of residue $\mathrm{D}$ and $\mathrm{E}$ were conducted in the same manner through COSY, NOESY, and HSQC spectra. Based on the previous literatures and data $[20,28,29]$, residue $D$ and residue E were determined as $\alpha$-L-Araf $-1 \rightarrow$ and $\rightarrow 4,6)-\alpha-\mathrm{D}-\mathrm{Gal} p-(1 \rightarrow$, respectively. All the chemical shifts of ${ }^{13} \mathrm{C}$ NMR and ${ }^{1} \mathrm{H}$ NMR on glycosyl residues $(\mathrm{A}, \mathrm{B}, \mathrm{C}, \mathrm{D}$, and E) were assigned in Table 2 which were derived from COSY (Figure 3C), HSQC, HMBC, and NOESY (Figure 3F) spectra. 
Table 2. Assignments of ${ }^{1} \mathrm{H}$ NMR and ${ }^{13} \mathrm{C}$ NMR Chemical shift ( $\delta$ ) of SMP-3a on the basis of COSY, HSQC, HMBC, and NOESY spectra (the bold values indicate the linkage position).

\begin{tabular}{cccccccc}
\hline \multirow{2}{*}{ Glycosyl Residues } & C1 & C2 & C3 & C4 & C5 & C6 & \\
\cline { 2 - 8 } & H1 & H2 & H3 & H4 & H5/H5a & H5b/H6a & H6b \\
\hline$\rightarrow 5)-\alpha$-L-Araf- $(1 \rightarrow$ & 108.81 & 82.11 & 78.05 & 83.61 & 68.20 & & \\
A & 5.00 & 4.04 & 3.92 & 4.12 & 3.79 & 3.72 & \\
$\rightarrow 4)-\alpha$-D-GalpA- $(1 \rightarrow$ & 100.55 & 69.49 & 69.98 & 79.04 & 72.08 & 175.13 & \\
B & 4.99 & 3.67 & 3.92 & 4.34 & 4.71 & & \\
$\rightarrow$ (2)- $\alpha$-L-Rhap- $(1 \rightarrow$ & 100.07 & 77.70 & 70.70 & 73.22 & 70.58 & 17.83 & \\
C & 5.15 & 4.03 & 3.78 & 3.33 & 3.64 & 1.16 & 1.22 \\
$\alpha$-L-Araf- $(1 \rightarrow$ & 110.50 & 83.40 & 77.65 & 79.26 & 62.21 & & \\
D & 5.16 & 4.12 & 4.03 & 4.34 & 3.64 & 3.72 & \\
$\rightarrow 4,6)-\alpha-D-G a l p-(1 \rightarrow$ & 98.94 & 70.80 & 77.60 & 78.40 & 69.12 & 66.80 & \\
E & 4.94 & 3.81 & 4.02 & 4.35 & 3.83 & 3.68 & 3.76 \\
\hline
\end{tabular}

HMBC and NOESY spectrum are efficient methods for the analysis of glycosidic linkages between sugar residues [30]. Based on the ${ }^{1} \mathrm{H}_{-}{ }^{13} \mathrm{C}$ HMBC spectrum (Figure 3E), a correlation peak was observed between H-1 ( $\delta 4.99 \mathrm{ppm})$ of residue B and C-4 ( $\delta 78.4 \mathrm{ppm})$ of residue E (B H1/E C4), which indicated the presence of $\rightarrow 4)-\alpha$-D-GalpA-( $1 \rightarrow 4), 6-\alpha-\mathrm{D}-\mathrm{Gal} p-(1 \rightarrow$. A cross peak between C-1 of residue $\mathrm{D}$ and H-5 of residue A was observed, which suggested the presence of $\alpha$-L-Araf-( $1 \rightarrow 5)-\alpha-\mathrm{L}-\mathrm{Araf}-(1 \rightarrow$. Similarly, the correlation peaks at $\delta 108.81 / 3.68 \mathrm{ppm}$ (A C1/E H6), $\delta 108.81 / 3.79 \mathrm{ppm}$ (A C1/A H5), and $\delta 5.00 / 68.20 \mathrm{ppm}$ (A H1/A C5) demonstrated the existence of $\rightarrow 5$ )- $\alpha$-L-Araf-(1 $\rightarrow 6), 4-\alpha$-D-Gal $p-(1 \rightarrow$ and $\rightarrow 5$ )- $\alpha$-L-Araf-( $(1 \rightarrow 5)-\alpha$-L-Araf-( $1 \rightarrow$. Then, the cross peaks at $\delta 4.99 / 4.35$ (B H1/E H4), $\delta 5.00 / 3.68$ (A H1/E H6a), $\delta 5.15 / 4.34$ (D H1/A H5a), and $\delta 5.00 / 3.79$ (A H1/A H5) in the ${ }^{1} \mathrm{H}-{ }^{1} \mathrm{H}$ NOESY spectrum proved the results of the HMBC spectrum. In addition, the cross peaks at $\delta 5.15 / 4.34$ (C H1/B $\mathrm{H} 4)$ and $\delta 4.94 / 4.03$ (E H1/C H2) verified the presence of $\rightarrow 2)-\alpha-\mathrm{L}-\mathrm{Rhap}-(1 \rightarrow 4)-\alpha-\mathrm{D}-\mathrm{Gal} p \mathrm{~A}-(1 \rightarrow$ and $\rightarrow 4,6)-\alpha$-D-Galp-(1 $\rightarrow 2)-\alpha$-L-Rhap- $(1 \rightarrow$.

Based on the above mentioned analysis, chemical structure of repeating unit of SMP-3a was established. The main chain of SMP-3a was detected to be $\rightarrow 2)$ - $\alpha$-L-Rha $p-(1 \rightarrow 4)-\alpha-\mathrm{D}-$ Gal $p$ A- $(1 \rightarrow 4)-\alpha$-D-Gal $p-(1 \rightarrow$ and the side chain was substituted at $O-6$ of $\rightarrow 4,6)-\alpha$-D-Galp-( $1 \rightarrow$. The branch of SMP-3a was composed of $\alpha$-L-Araf-( $1 \rightarrow$ and $\rightarrow 5)-\alpha$-L-Araf-( $1 \rightarrow$. Furthermore, the specific molecular structure of SMP-3a was deduced as shown below:

$$
\begin{aligned}
\alpha-L-A r a f-(1 \rightarrow 5)-\alpha-L-A r a f-(1 \rightarrow 5)-\alpha-L-A r a f-(1 \\
\\
\\
\rightarrow 2)-\alpha-L-R h a p-(1 \rightarrow 4)-\alpha-D-G a l p A-(1 \rightarrow 4)-\alpha-D-G a l p-(1 \rightarrow
\end{aligned}
$$

\subsection{Morphological Analysis}

The morphologies of SMP-3a was analyzed by SEM which is a powerful tool to analyze the surface morphology of polysaccharide and the results were displayed in Figure 2. As shown in Figure 2G,H with the different magnification (A: 200x, B: 5000x), the shape of SMP-3a was mainly lamellar or clastic, and the surface was smooth or wrinkle with a compact texture. The flake-like surface of SMP-3a was similar with the polysaccharides from Cyclocarya paliurus leaves [31] and purple sweet potato [32].

\subsection{Thermal Properties}

Thermal stability is also an important feature of materials that may have biological applications in view of the potential need for heat sterilization [33]. The thermodynamic properties of SMP-3a was detected by TGA, DTG, and DSC. As shown in Figure 2E, the first mass loss (17.75\%) ranged from $31.71{ }^{\circ} \mathrm{C}$ to $115.42^{\circ} \mathrm{C}$, for SMP-3a was mainly concerned with the loss of free and bound water, while the 
second mass loss (45.39\%) ranged from $230.44{ }^{\circ} \mathrm{C}$ to $367.94{ }^{\circ} \mathrm{C}$ was caused by thermal decomposition of SMP-3a. Finally, the $\mathrm{T}_{50}$ of SMP-3a was $265.47^{\circ} \mathrm{C}$ and the third weight loss was closely related to the oxidation of organic matter. The result indicated that SMP-3a was relatively stable below $230^{\circ} \mathrm{C}$.

The DSC curve (Figure 2F) further illustrated the thermal transition of SMP-3a. An obvious endothermic peak appeared at $150.67^{\circ} \mathrm{C}$, which could be caused by the dehydration or dehydroxylation reactions and the loss of peripheral polysaccharide chains [34]. The above results indicated that the SMP-3a had excellent thermal stability for application in the food and medical industries.

\subsection{Immunomodulatory Activity of SMP-3a}

Macrophages play an important role in the immune system. They can initiate the innate immune response and help fight infection and inflammation [13]. Thus, in the present study, RAW264.7 cells were used to investigate the immunoregulatory activity of SMP-3a in vitro. As shown in Figure 4A, SMP-3a could stimulate RAW264.7 cells proliferation effectively in a dose-dependent manner. Moreover, the cell proliferation rate increased from $126.8 \pm 5.6 \%$ at $12.5 \mu \mathrm{g} / \mathrm{mL}$ to $189 \pm 8.1 \%$ at $400 \mu \mathrm{g} / \mathrm{mL}$.

A

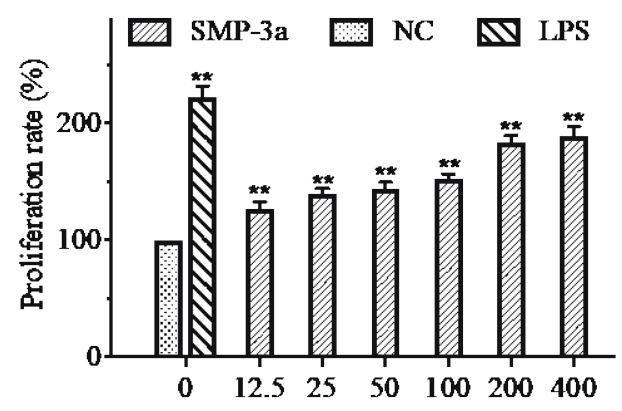

Concentration of SMP-3a $(\mu \mathrm{g} / \mathrm{mL})$

C

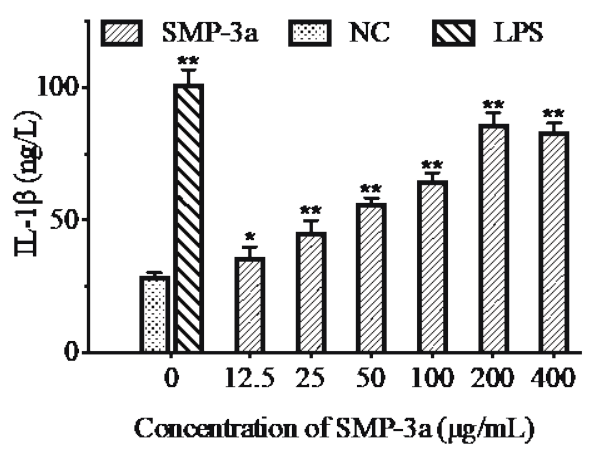

B

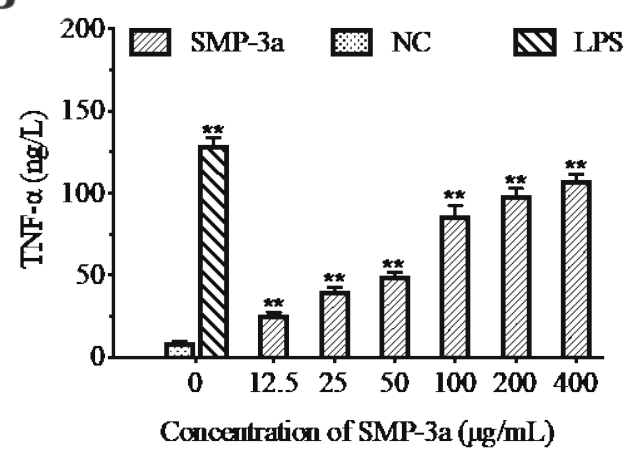

D

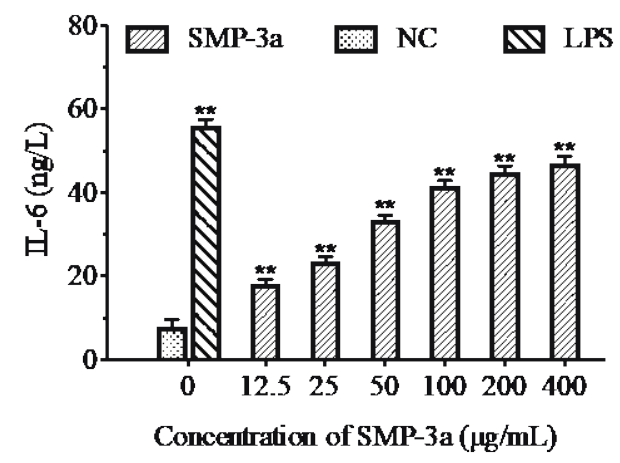

Figure 4. Effect of SMP-3a on the proliferation of RAW264.7 murine macrophage cells (A). Effect of SMP-3a on the production of cytokines TNF- $\alpha$ (B), IL-1 $\beta$ (C), and IL-6 (D) in RAW264.7 murine macrophage cells. $1 \mu \mathrm{g} / \mathrm{mL}$ LPS was added as positive group. Data are presented as mean $\pm \mathrm{SD}(\mathrm{n}=3)$. ${ }^{*} p<0.05,{ }^{* *} p<0.01$ compared with the negative control (NC).

Cytokines are intercellular signaling proteins with a wide range of biological activities that secreted by both immune and non-immune cells [13]. Macrophages can kill pathogens and regulate immune responses by producing proinflammatory cytokines, such as TNF- $\alpha$, IL-1 $\beta$ and IL-6. As shown in Figure 4, the production of TNF- $\alpha$, IL-1 $\beta$, and IL-6 in the negative control was low. However, the level of TNF- $\alpha$, IL- $1 \beta$ and IL- 6 increased significantly after the treatment with different concentrations of SMP-3a. At the concentration of $12.5-400 \mu \mathrm{g} / \mathrm{mL}$, the highest production of TNF- $\alpha(108 \pm 3.6 \mathrm{ng} / \mathrm{L})$ and IL-6 $(47 \pm 1.7 \mathrm{ng} / \mathrm{L})$ were obtained at $400 \mu \mathrm{g} / \mathrm{mL}$, while the highest level of IL-1 $\beta$ reached $86.4 \pm 4.1 \mathrm{ng} / \mathrm{L}$ at $200 \mu \mathrm{g} / \mathrm{mL}$. The results indicated that SMP-3a could obviously promote the secretion of TNF- $\alpha$, IL-1 $\beta$, and IL-6 in RAW 264.7 cells in a concentration-dependent manner. 


\section{Conclusions}

A new acid, heteropolysaccharide SMP-3a, was successfully isolated and purified from Solanum muricatum pulp. Structural analysis revealed that SMP-3a was mainly consisted of rhamnose, arabinose, galactose, and galacturonic acid with the molar ratio of 1.09:2.64:1.54:1. Methylation and NMR analysis indicated that the backbone of SMP-3a was deduced as $\rightarrow 2)-\alpha-\mathrm{L}-\mathrm{Rha} p-(1 \rightarrow 4)-\alpha$-D-Gal $p \mathrm{~A}-(1 \rightarrow 4)-\alpha-\mathrm{D}-$ Gal $p-(1 \rightarrow$ with branch at $O-6$ position of $\rightarrow 4,6)-\alpha-\mathrm{D}-\mathrm{Gal} p-(1 \rightarrow$. The side chain was consisted of $\alpha$-L-Araf- $(1 \rightarrow$ and $\rightarrow 5)-\alpha$-L-Araf- $(1 \rightarrow$. Preliminary activity tests manifested that SMP-3a exhibited immunomodulatory activity in a dose-dependent manner within the concentration range of $12.5-400 \mu \mathrm{g} / \mathrm{mL}$. Specifically, SMP-3a enhanced the proliferation of macrophages as well as stimulated macrophages to release proinflammatory cytokines. In summary, SMP-3a could be explored as a potential new source of natural immunomodulator with thermal stability for use in food, healthcare, and medical industries.

Author Contributions: Conceptualization, H.Y. and W.W.; Methodology, H.Y.; Software, H.Y. and X.L.; Validation, H.Y. and Q.X.; Formal Analysis, H.Y.; Investigation, H.Y. and Q.X.; Resources, W.W. and J.X.; Data Curation, H.Y. and W.W.; Writing-Original Draft Preparation, H.Y.; Writing-Review \& Editing, H.Y., J.E. and W.W.; Supervision, W.W. and J.X.; Funding Acquisition, W.W.

Funding: This work was supported by the National Natural Science Foundation of China (No. 81502955, 81750110548); the Shanghai Innovation Action Plan (No. 17490742500); and the Jiangsu Provincial Natural Science Foundation (BK20151282).

Conflicts of Interest: The authors declare no conflict of interest.

\section{References}

1. Kumar, A.; Adak, T.; Rajan, S. Pepino (Solanum muricatum Ait.): A potential future crop for subtropics. Trop. Plant Res. 2017, 4, 514-517. [CrossRef]

2. Martínez-Romero, D.; Serrano, M.; Valero, D. Physiological changes in pepino (Solanum muricatum Ait.) fruit stored at chilling and non-chilling temperatures. Postharvest Biol. Technol. 2003, 30, 177-186. [CrossRef]

3. Kola, O.; Simsek, M.; Duran, H.; Bozkir, H. HPLC determination of carotenoid, organic acid, and sugar content in pepino (Solanum muricatum) fruit during the ripening period. Chem. Nat. Compd. 2015, 51, 132-135. [CrossRef]

4. Shathish, K.; Guruvayoorappan, C. Solanum muricatum Ait. inhibits inflammation and cancer by modulating the immune system. J. Cancer Res. Ther. 2014, 10, 623-630.

5. Prohens, J.; Nuez, F.; Kollmannsberger, H.; Nitz, S.; Rodríguez-Burruezo, A. Analysis of the Volatile Aroma Constituents of Parental and Hybrid Clones of Pepino (Solanum muricatum). J. Agric. Food Chem. 2007, 52, 5663-5669.

6. Hsu, C.C.; Guo, Y.R.; Wang, Z.H.; Yin, M.C. Protective effects of an aqueous extract from pepino (Solanum muricatum Ait.) in diabetic mice. J. Sci. Food Agric. 2011, 91, 1517-1522. [CrossRef]

7. Yu, Y.; Shen, M.; Song, Q.; Xie, J. Biological activities and pharmaceutical applications of polysaccharide from natural resources: A review. Carbohydr. Polym. 2018, 183, 91-101. [CrossRef]

8. Wang, M.; Zhu, P.; Zhao, S.; Nie, C.; Wang, N.; Du, X.; Zhou, Y. Characterization, antioxidant activity and immunomodulatory activity of polysaccharides from the swollen culms of Zizania latifolia. Int. J. Biol. Macromol. 2017, 95, 809-817. [CrossRef]

9. Li, J.E.; Nie, S.P.; Xie, M.Y.; Li, C. Isolation and partial characterization of a neutral polysaccharide from Mosla chinensis Maxim. cv. Jiangxiangru and its antioxidant and immunomodulatory activities. J. Funct. Foods 2014, 6, 410-418. [CrossRef]

10. Seedevi, P.; Moovendhan, M.; Viramani, S.; Shanmugam, A. Bioactive potential and structural chracterization of sulfated polysaccharide from seaweed (Gracilaria corticata). Carbohydr. Polym. 2017, 155, 516-524. [CrossRef]

11. Ding, X.; Zhu, F.; Gao, S. Purification, antitumour and immunomodulatory activity of water-extractable and alkali-extractable polysaccharides from Solanum nigrum L. Food Chem. 2012, 131, 677-684. [CrossRef] 
12. Zhu, K.; Zhang, Y.; Nie, S.; Xu, F.; He, S.; Gong, D.; Wu, G.; Tan, L. Physicochemical properties and in vitro antioxidant activities of polysaccharide from Artocarpus heterophyllus Lam. pulp. Carbohydr. Polym. 2017, 155, 354-361. [CrossRef] [PubMed]

13. Sun, H.; Zhang, J.; Chen, F.; Chen, X.; Zhou, Z.; Wang, H. Activation of RAW264.7 macrophages by the polysaccharide from the roots of Actinidia eriantha and its molecular mechanisms. Carbohydr. Polym. 2015, 121, 388-402. [CrossRef] [PubMed]

14. Du, H.; Chen, J.; Tian, S.; Gu, H.; Li, N.; Sun, Y.; Ru, J.; Wang, J. Extraction optimization, preliminary characterization and immunological activities in vitro of polysaccharides from Elaeagnus angustifolia L. pulp. Carbohydr. Polym. 2016, 151, 348-357. [CrossRef] [PubMed]

15. DuBois, M.; Smith, F.; Rebers, P.A.; Gilles, K.A.; Hamilton, J.K. Colorimetric Method for Determination of Sugars and Related Substances. Anal. Chem. 1956, 28, 350-356. [CrossRef]

16. Liu, Y.; Su, P.; Xu, J.; Chen, S.; Zhang, J.; Zhou, S.; Wang, Y.; Tang, Q.; Wang, Y. Structural characterization of a bioactive water-soluble heteropolysaccharide from Nostoc sphaeroids kütz. Carbohydr. Polym. 2018, 200, 552-559. [CrossRef]

17. Taylorf, R.L.; Conrad, H.E. Stoichiometric Depolymerization of Polyuronides and Glycosaminoglycuronans to Monosaccharides following Reduction of Their Carbodiimide-Activated Carboxyl Groups. Biochemistry 1972, 11, 1383-1388. [CrossRef]

18. Bradford, M.M. A rapid and sensitive method for the quantitation of microgram quantities of protein utilizing the principle of protein-dye binding. Anal. Biochem. 1976, 72, 248-254. [CrossRef]

19. Blumenkrantz, N.; Asboe-Hansen, G. New method for quantitative determination of uronic acids. Anal. Biochem. 1973, 54, 484-489. [CrossRef]

20. Zhang, H.; Li, W.J.; Nie, S.P.; Chen, Y.; Wang, Y.X.; Xie, M.Y. Structural characterisation of a novel bioactive polysaccharide from Ganoderma atrum. Carbohydr. Polym. 2012, 88, 1047-1054. [CrossRef]

21. Chen, M.M.; Wu, J.; Shi, S.; Chen, Y.; Wang, H.; Fan, H.; Wang, S. Structure analysis of a heteropolysaccharide from Taraxacum mongolicum Hand.-Mazz. and anticomplementary activity of its sulfated derivatives. Carbohydr. Polym. 2016, 152, 241-252. [CrossRef] [PubMed]

22. Needs, P.W.; Selvendran, R.R. Avoiding oxidative degradation during sodium hydroxide/methyl iodide-mediated carbohydrate methylation in dimethyl sulfoxide. Carbohydr. Res. 1993, 245, 1-10. [CrossRef]

23. Chen, Y.; Li, X.H.; Zhou, L.Y.; Li, W.; Liu, L.; Wang, D.D.; Zhang, W.N.; Hussain, S.; Tian, X.H.; Lu, Y.M. Structural elucidation of three antioxidative polysaccharides from Tricholoma lobayense. Carbohydr. Polym. 2017, 157, 484-492. [CrossRef] [PubMed]

24. Nie, C.; Zhu, P.; Ma, S.; Wang, M.; Hu, Y. Purification, characterization and immunomodulatory activity of polysaccharides from stem lettuce. Carbohydr. Polym. 2018, 188, 236-242. [CrossRef] [PubMed]

25. Liu, Y.; Zhang, B.; Ibrahim, S.A.; Gao, S.S.; Yang, H.; Huang, W. Purification, characterization and antioxidant activity of polysaccharides from Flammulina velutipes residue. Carbohydr. Polym. 2016, 145, 71-77. [CrossRef] [PubMed]

26. Zhang, Z.; Kong, F.; Ni, H.; Mo, Z.; Wan, J.B.; Hua, D.; Yan, C. Structural characterization, $\alpha$-glucosidase inhibitory and DPPH scavenging activities of polysaccharides from guava. Carbohydr. Polym. 2016, 144, 106-114. [CrossRef]

27. Ren, Y.Y.; Zhu, Z.Y.; Sun, H.Q.; Chen, L.J. Structural characterization and inhibition on $\alpha$-glucosidase activity of acidic polysaccharide from Annona squamosa. Carbohydr. Polym. 2017, 174,1-12. [CrossRef]

28. Zhang, Q.; Cheng, M.; Mou, X.; Zhang, X.; Lv, J.; Fan, Q.; Cao, K.; Xu, Y.; Wu, Y. Structure characterization of two functional polysaccharides from Polygonum multiflorum and its immunomodulatory. Int. J. Biol. Macromol. 2018, 113, 195-204. [CrossRef]

29. Liu, W.; Liu, Y.; Zhu, R.; Yu, J.; Lu, W.; Pan, C.; Yao, W.; Gao, X. Structure characterization, chemical and enzymatic degradation, and chain conformation of an acidic polysaccharide from Lycium barbarum $\mathrm{L}$. Carbohydr. Polym. 2016, 147, 114-124. [CrossRef]

30. Zhao, J.; Wu, M.; Liu, J.; Yang, Z.; Shang, F. Structural analysis of a homogeneous polysaccharide from Achatina fulica. Int. J. Biol. Macromol. 2017, 98, 786-792.

31. Xie, J.H.; Zhang, F.; Wang, Z.J.; Shen, M.Y.; Nie, S.P.; Xie, M.Y. Preparation, characterization and antioxidant activities of acetylated polysaccharides from Cyclocarya paliurus leaves. Carbohydr. Polym. 2015, 133, 596-604. [CrossRef] [PubMed] 
32. Wu, Q.; Qu, H.; Jia, J.; Kuang, C.; Wen, Y.; Yan, H.; Gui, Z. Characterization, antioxidant and antitumor activities of polysaccharides from purple sweet potato. Carbohydr. Polym. 2015, 132, 31-40. [CrossRef] [PubMed]

33. Chen, Y.; Xue, Y. Purification, chemical characterization and antioxidant activities of a novel polysaccharide from Auricularia polytricha. Int. J. Biol. Macromol. 2018, 120, 1087-1092. [CrossRef] [PubMed]

34. Guo, M.Z.; Meng, M.; Duan, S.Q.; Feng, C.C.; Wang, C.L. Structure characterization, physicochemical property and immunomodulatory activity on RAW264.7 cells of a novel triple-helix polysaccharide from Craterellus cornucopioides. Int. J. Biol. Macromol. 2019, 126, 796-804. [CrossRef]

(C) 2019 by the authors. Licensee MDPI, Basel, Switzerland. This article is an open access article distributed under the terms and conditions of the Creative Commons Attribution (CC BY) license (http://creativecommons.org/licenses/by/4.0/). 